\title{
Herpetological Journal \\ https://doi.org/10.33256/hj30.3.126134 \\ Carry-over effects of the larval environment on the post-metamorphic performance of Bombina variegata (Amphibia, Anura)
}

\author{
Ulrich Sinsch ${ }^{1}$, Fabienne Leus ${ }^{1}$, Marlene Sonntag ${ }^{1}$ \& Alena Marcella Hantzschmann ${ }^{1}$
}

${ }^{1}$ Institute of Integrated Sciences, Department of Biology, University of Koblenz-Landau, Universitätsstr. 1, D-56070 Koblenz, Germany

\begin{abstract}
Metamorphs of the yellow-bellied toad, Bombina variegata, vary widely in size at metamorphosis in the field. We performed a replicated outdoor mesocosm study to simulate the environmental factor combinations in permanent and ephemeral breeding sites and to quantify their effects on tadpole development (duration of the larval period, metamorph size and body condition). Looking for potential carry-over effects of the larval environment, we quantified locomotor performance of all metamorph phenotypes originating from the mesocosms immediately after metamorphosis under controlled conditions. In contrast to the prediction of life-history theory, tadpoles were unable to adjust developmental rate to water availability, but metamorphs originating from the ephemeral pond treatment were smaller and had a lower body condition than those from the permanent pond treatment. Size-dependent carry-over effects included the length of the first jump following tactile stimulation, burst performance (total length of spontaneous jumps) and endurance (total distance covered in 10 forced jumps). A size-independent effect of larval environment was the prolonged locomotor effort to escape (5.7 consecutive jumps following initial stimulus) of metamorphs from the ephemeral pond treatment compared to same-sized ones (3.7 jumps) from the permanent pond treatment. Thus, we demonstrate that carry-over effects of larval environment on metamorph phenotype and behaviour cause a considerable variation in fitness in the early terrestrial stage of B. variegata. Informed conservation management of endangered populations in the northern range should therefore include the provision of small permanent breeding ponds promoting larger and fitter metamorphs.
\end{abstract}

Keywords: complex life cycles, mesocosm, plasticity of metamorph phenotype, post-metamorphic jumping performance, delayed density dependence, delayed life-history effects

\section{INTRODUCTION}

$D_{\mathrm{t}}^{\mathrm{e}}$ evelopmental plasticity is the property of a genotype to produce different phenotypes in response to the environmental conditions experienced during development (Denver \& Middlemis-Maher, 2010; Gritti \& Barbot, 2019). In organisms with complex lifehistory such as amphibians, environmental conditions experienced during the aquatic larval stage influence the timing of metamorphosis as well as morphological and behavioural features of the terrestrial metamorph (Alford \& Harris, 1988; Crespi \& Warne, 2013). In natural tadpole habitats, often subject to desiccation at unpredictable rates, environmental factor combinations vary considerably in time and space during tadpole development, e.g. nutrient resources and available space decrease, whereas tadpole density and the amplitude of temperature fluctuations increase simultaneously (Newman, 1998; Turner et al., 2000). The consequences of the complex interactions among these and other factors on metamorph features are hard to predict from experimental approaches focusing on the impact of a single environmental factor (Brady \& Griffiths, 2000). For example, tadpole density (=crowding; Richards, 1958) does not only affect morphology (metamorph size), but also physiology and behaviour (stress hormone concentrations; corticotropin-releasing hormone, glucocorticoids) (Denver, 1997; Brady \& Griffiths, 2000; Crespi \& Warne, 2013). Thus, metamorph plasticity and its possible consequences for fitness/survival of juveniles and adults remain a major challenge for ecologists studying amphibians that inhabit variable environments.

Available evidence suggests that environmental conditions in the aquatic habitat may cause variation in adult phenotypic expression of several life-history traits (Alford \& Harris, 1988; Boes \& Benard, 2013; Yagi \& Green, 2018; Moore \& Martin, 2019). The variation of traits such as size at and timing of metamorphosis often implies carry-over effects from larval conditions to the future fitness of juveniles and adults (Pechenik, 2006; Van Allen et al., 2010). Keeping in mind that stagespecific environmental effects are often not independent from each other and may combine in complex ways to shape fitness aspects, the correlation of single 
traits to adult fitness has to be proven experimentally (Beckerman et al., 2002; De Block \& Stoks, 2005; Van Allen et al., 2010). In amphibians, there is substantial evidence for the link between large metamorph size and increased dispersal abilities, survival and reproductive success (e.g., Altwegg \& Reyer, 2003; Vonesh, 2005; Chelgren et al., 2006; Reading, 2007; Briggs, 2008; Tarvin et al., 2015; Yagi \& Green, 2018). In some frog species, however, the growth rate and fitness of juveniles did not only depend on the metamorphs' phenotype, but also independently on features of the larval habitat (Morey \& Reznick, 2001; Álvarez \& Nicieza, 2002a, b; Richter-Boix et al., 2006; Van Allen et al., 2010; Bredeweg et al., 2019; Zamora-Camacho et al., 2019). Interactions among the aquatic conditions experienced, variation of metamorph features, and fitness of the terrestrial stages seem to occur frequently in pond-breeding amphibians.

The yellow-bellied toad (Bombina variegata) is an excellent model to analyse these interactions because size of metamorphs varies in a remarkably broad range in the wild (Kapfberger, 1984; Barandun \& Reyer, 1997a; Miesler \& Gollmann, 2000; Di Cerbo \& Biancardi, 2010; Dittrich et al., 2016; Schäfer et al., 2018). The ecological features of breeding ponds are comparably broad and range from water bodies with a short hydroperiod (high risk of desiccation before metamorphosis) to permanent ponds (numerous predators, competing tadpoles of other species) (Barandun \& Reyer, 1997b; Hartel et al., 2007; Hantzschmann \& Sinsch, 2019). Yet, there is no evidence that environmental factor combinations experienced during aquatic development are the proximate causes of plasticity in metamorph traits. Böll (2002) attempted to induce phenotypic plasticity in developmental rate and metamorph size under controlled conditions, but results were inconsistent with field observations. Tadpoles reared in desiccating habitats metamorphosed as expected at a small size, but developmental rate decreased instead of speeding up. The presence of carry-over effects from larval history to the performance of metamorph phenotypes has not been tested yet in $B$. variegata.

Therefore, we designed a replicated mesocosm study to establish the causal relationship between aquatic environment and metamorph features and to quantify potential carry-over effects on post-metamorphic performance mediated by metamorph features. To maximise impact, we tested the most contrasting larval environments used by free-ranging $B$. variegata: (1) permanent pond conditions, i.e. constant water level and volume during the complete larval development, and (2) ephemeral pond conditions, i.e. initial water level and volume successively decreasing as during the desiccation of a natural pond. Rearing conditions aimed to mimic the factor combinations acting at the extremes of the natural hydroperiod continuum used for breeding. Life-history theory predicts that the permanent pond environment should yield large metamorphs at slow developmental rate and the ephemeral treatment small metamorphs at fast growing rates (Wilbur \& Collins, 1973; Stearns, 2000). We hypothesise that the aquatic environment experienced shapes the plasticity of metamorph features and subsequently the locomotor performance of the metamorphs (indicator of fitness). We predict: (1) pond conditions determine timing of metamorphosis and metamorph phenotype (size, body condition). (2) metamorph phenotypes differ in jumping performance. (3) similar phenotypes resulting from either larval treatment have similar locomotor performance.

\section{METHODS}

\section{Ethics statement}

Permits for the collection of yellow-bellied toad Bombina variegata tadpoles were issued by the Struktur- und Genehmigungsdirektion Nord (Az 425-104.1711). All applicable institutional and/or national guidelines for the care and use of animals were followed (Kreisverwaltung Mayen-Koblenz, Az 39183-04). All toad metamorphs were released at the site of capture after testing jumping performance.

\section{Animal collection}

On 3 July 2017, we collected 360 tadpoles from four ponds at the former military training area Schmidtenhöhe near Koblenz $\left(50.201-50.346^{\circ} \mathrm{N}, 7.393-7.644^{\circ} \mathrm{E}, 279-298\right.$ $\mathrm{m}$ a.s.I.; Rhineland-Palatinate, Germany; Schäfer et al., 2018; Hantzschmann \& Sinsch, 2019). Three of the ponds sampled dried out during the next two weeks; the fourth had a hydroperiod long enough to warrant successful larval development. We immediately transferred all tadpoles to University of Koblenz, where we placed them altogether into a $100 \mathrm{~L}$ indoor plastic pan filled with $50 \mathrm{~L}$ of aged tap water. At the day of capture, we measured the developmental stage (range: 26-35; Gosner, 1960) and body length (to the nearest $0.5 \mathrm{~mm}$; range: 4.5 $15 \mathrm{~mm}$ ) of each tadpole using a dissecting microscope (Zeiss Stemi 508). We randomly constituted 20 groups of 18 tadpoles that were assigned to plastic boxes with $1 \mathrm{~L}$ aged tap water. The groups of tadpoles were transferred to outdoor mesocosms (plastic pans) for experimental treatment.

\section{Experimental conditions of tadpole rearing}

The experimental set-up consisted of two rows of 10 fully sun-exposed, outdoor mesocosms (60 x $40 \times 20$ $\mathrm{cm})$ each, filled with initially $40 \mathrm{~L}$ of tap water $(16 \mathrm{~cm}$ water height). We filled the mesocosms with tap water one week before the start of the experiment. In each mesocosm, we added a $3 \mathrm{~mm}$ ground layer of soil collected at the Schmidtenhöhe and a pasture sod (10 $\mathrm{x}$ $10 \mathrm{~cm}$ ) to mimic the conditions at the natural breeding sites. Food available to tadpoles consisted, apart from an initial dose of $1 \mathrm{~g}$ Tetraphyll, of bacteria, algae and other microorganisms introduced with soil and sod. We covered the mesocosm surface completely with gauze to prevent litter from falling into the water, interference with airborne predators (e.g., birds, dytiscid beetles) and escape of metamorphs at the end of the experiment. On the day of capture, we randomly assigned the 20 groups of tadpoles to one of two regimes mimicking the extremes of hydrological breeding pond variation: (1) Permanent pond treatment: $\mathrm{PP}=$ constant water level 
at $16 \mathrm{~cm}$ height plus one large free-ranging dragonflylarva (Aeshna cyanea) as a potential aquatic predator. Potential additional effects of interspecific competition were not considered because in the permanent ponds of the study area used by $B$. variegata, tadpoles of the sympatric Pelophylax esculentus, Hyla arborea and Alytes obstetricans were rare to absent. (2) Ephemeral pond treatment: $E P=$ decreasing water level from initially $16 \mathrm{~cm}$ to 11,8 , and $5 \mathrm{~cm}$ at weekly steps (final water volume 12 L) without predators. Two mesocosms of each treatment group were fitted with temperature loggers (Tinytag Plus 2 -TGP 4017) recording hourly water temperature. Note that the two treatments were chosen deliberately to evaluate the combined impact of the factors predator presence, tadpole density and natural water temperature fluctuations on tadpole development and metamorph features, not to disentangle the isolated effects of the single factors, which always interact in natural breeding ponds.

Tadpole development was monitored during six weeks. The number of surviving tadpoles was counted weekly, body length and Gosner-stage were measured biweekly. When we recorded the first metamorphic stages, we checked the mesocosms every two days to avoid drowning of metamorphs. We defined Gosner-stage 42 as the endpoint of complete aquatic development, removed these individuals from the rearing mesocosm and placed them into same-sized pans (one per treatment group) within a temperature-controlled chamber at 20 ${ }^{\circ} \mathrm{C}$. These pans contained $2 \mathrm{~L}$ water and were inclined to allow tadpoles to leave the water at will.

Experimental testing of metamorph jumping behaviour Resorption of the tail bud occurred usually within two days. Prior to testing, snout-vent length (SVL) of metamorphs was measured using a calliper (rounded to the nearest $0.5 \mathrm{~mm}$ ). Following gently removing water drops on skin surface with a paper towel, we measured the corresponding body mass using a Sartorius electronic balance (to the nearest $\mathrm{mg}$ ). Metamorphs were not fed because body mass during testing should reflect exclusively larval growth performance. The body condition of an individual is calculated as the studentised residual of the SVL-mass relationship using a multiplicative model $\ln$ (mass) $=\mathrm{a}+\mathrm{b} \times \ln (\mathrm{SVL})$, with $\mathrm{a}=$ intercept and $b=$ slope (residual index, Băncilă et al., 2010; Scheele et al., 2014; Mikoláš, 2016). We transferred metamorphs immediately following measurements to a temperaturecontrolled chamber at $20^{\circ} \mathrm{C}$ with artificial light. Thermal acclimation lasted two hours before testing.

Trials were performed in a white plastic box $(60 \times 40$ $x 20 \mathrm{~cm}$ ) without any structure. The ground of the pan was cleaned and moistened with a paper towel before introducing the test individual. A digital camera was fixed $50 \mathrm{~cm}$ above the ground level of the pan to record the movements of the metamorph during the trial. Before any trial, the scale was calibrated by recording a $50 \mathrm{~cm}$ ruler at the ground of the pan. Each metamorph was tested once. A trial consisted of placing a metamorph into the pan and pushing it gently at the urostyle using a pencil. This tactile stimulus elicited a series of jumps in most individuals. Unresponsive metamorphs were excluded from data analysis. If the initial stimulus elicited fewer than 10 jumps, the individual was stimulated again to complete 10 jumps. The trial was finished after 10 jumps and the metamorph was removed from the testing pan. The digital record of each trial was labelled with number of the individual tested, SVL, body mass and prior larval treatment. Every two days, the tested individuals were released again at the collecting site.

The locomotor performance of metamorphs was analysed using the program Tracker (Open Source Physics, version 4.11.0; https://physlets.org/tracker/). We quantified four parameters to describe the jumping behaviour of metamorphs (Tejedo et al., 2000; RichterBoix et al., 2006): (1) number of spontaneous jumps following the tactile stimulus (=intensity of locomotor escape behaviour). (2) distance [ $\mathrm{mm}$ ] covered by each spontaneous jump (snout tip of the metamorph was defined as start and end point of a jump). (3) total distance $[\mathrm{mm}]$ covered in all spontaneous jumps (=burst performance). (4) total distance [mm] covered in 10 successive jumps following one or more tactile stimuli (=endurance; McGinley et al., 2013).

\section{Statistical analyses}

Data distributions were tested for normality determining standardised kurtosis and skewness. Since distributions often deviated from normality, all data were log10transformed to normalise them for parametric procedures. We tested for carry-over effects of the larval treatment on the response variables using ANCOVAs with the continuous co-variates duration of larval treatment, SVL, body condition, depending on which response variable was analysed. Note that we did not account for potential differences among the 10 pans within a treatment due to logistical problems. Therefore, a potential increase of variability caused by a single pan remained statistically undetected. If one or two co-variates correlated significantly with a response variable, we used linear regression models (simple and multiple) to quantify the effect in each larval treatment. Differences of models with respect to slope or intercept were tested for using an ANOVA on the conditional sum of squares. Statistical significance was set at alpha=0.05. Statistical analyses were conducted using the software package StatGraphics 18

\section{RESULTS}

\section{Tadpole performance under permanent and ephemeral pond treatments}

Water temperatures fluctuated between $13.1{ }^{\circ} \mathrm{C}$ and $35.3{ }^{\circ} \mathrm{C}$ during the EP treatment and $13.5^{\circ} \mathrm{C}$ and 35.9 ${ }^{\circ} \mathrm{C}$ during the PP treatment (Fig. S1). Minimum diel water temperature (log10-transformed) did not differ significantly between EP and PP (ANOVA, $F_{1,151}=1.89$, $\mathrm{P}=0.1715)$. In contrast, maximum diel water temperature and the range of diel fluctuations (all response variables log10-transformed) were significantly higher in the EP mesocosms than in the PP mesocosms (ANOVA, maximum: $F_{1,151}=4.59, P=0.0338$; range: $F_{1,151}=6.14$, 


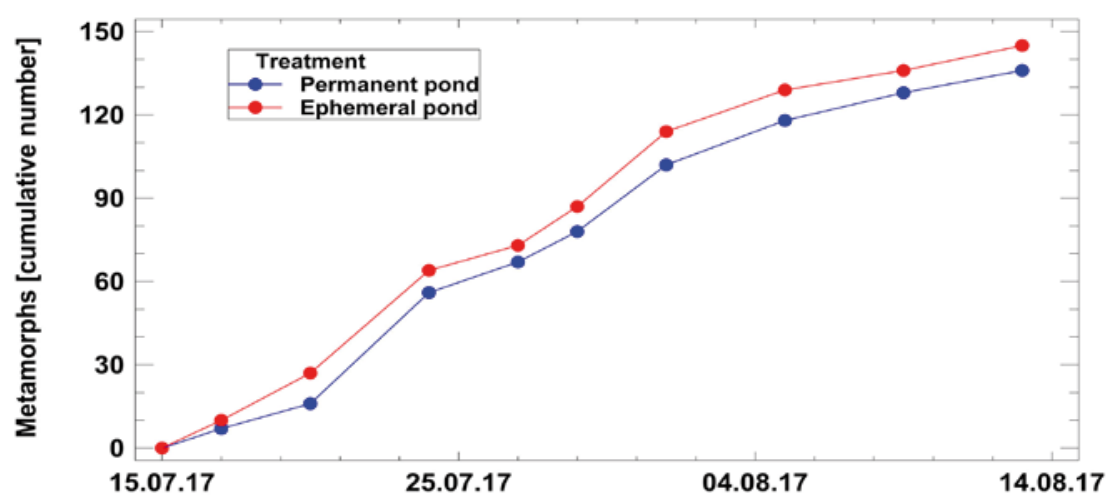

Figure 1. Time course of metamorphosis in B. variegata tadpoles exposed to constant water level (permanent pond treatment) or decreasing water level (ephemeral pond treatment). Data pooled for the 10 replicates per treatment.

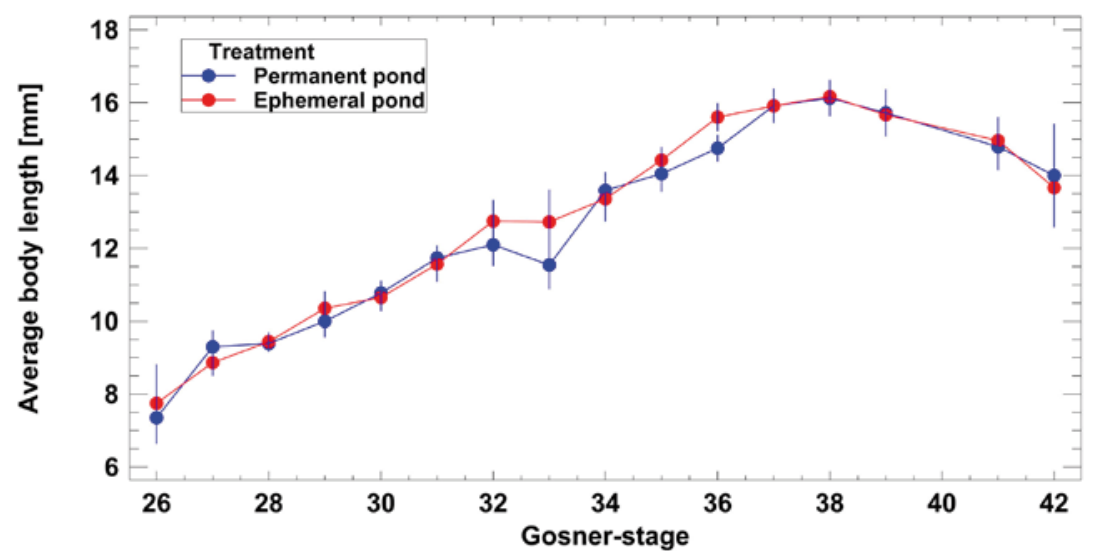

Figure 2. Growth pattern of B. variegata tadpoles in the two experimental treatments. Development is staged according to Gosner (1960), body size is given as the average body length [mm] and corresponding $95 \%$ Bonferroni confidence interval. Data pooled for the 10 replicates per treatment.

$P=0.0143)$, reflecting the effect of decreasing water level.

During the experimental treatments, 19 tadpoles (10.6\%) died in EP and 23 tadpoles (12.8 \%) in PP. The mortality rate of tadpoles was not significantly affected by treatment (ANCOVA, $\mathrm{F}_{1,79}=0.02, \mathrm{P}=0.8931$ ) and did not vary in time (ANCOVA, $F_{1,79}=0.30, P=0.5837$ ). During the EP treatment, 145 tadpoles (80.6\%) reached the metamorphic stage 42, during the PP treatment 136 $(75.6 \%)$ did. The number (log10-transformed) of metamorphs per mesocosm was not significantly affected by treatment (ANCOVA, $\mathrm{F}_{1,19}=0.73, \mathrm{P}=0.4038$ ). The time course of metamorphosis was similar in the EP and PP tadpoles (Fig. 1). The difference between the cumulative number of metamorphs in the EP and PP mesocosms did not increase significantly with the duration of the experiment (all regression models tested: $P>0.05$ ). At the end of the experimental treatments, $16 \mathrm{EP}$ and $21 \mathrm{PP}$ tadpoles had not reached the metamorphic stage.

Tadpole body length increased continuously during the pre-metamorphic stages (26-38; linear regression model: $\mathrm{BL}[\mathrm{mm}]=-10.03+0.70 *$ Gosner-stage, $\mathrm{R}^{2}=82.1$ $\%, P<0.0001 ;$ Fig. 2). During metamorphosis (stages: $39-$ 45 ) body length shrank significantly (linear regression model: $\mathrm{BL}[\mathrm{mm}]=40.86-0.64 *$ Gosner-stage, $\mathrm{R}^{2}=47.6$ $\%, \mathrm{P}<0.0001 ;$ Fig. 2). Stage-adjusted pre-metamorphic tadpole size (log10-transformed) did not differ between the experimental treatments (ANCOVA, $F_{1,738}=2.15$, $P=0.1425$ ), but increased with Gosner-stage (ANCOVA, $\left.\mathrm{F}_{1,738}=2845, \mathrm{P}<0.0001\right)$.

Metamorph size decreased with date of emergence and was greater in the PP treatment (Fig. 3A). The linear regression models for EP metamorphs $(\log 10[S V L]=1.15-$ $0.0033 *$ day; $\left.R^{2}=41.6 \%, F_{1124}=87.58, P<0.0001\right)$ and $P P$ individuals ( $\log 10[S V L] 1.16-0.0020 *$ day; $R^{2}=17.3 \%$, $\mathrm{F}_{1,114}=23.67, \mathrm{P}<0.0001$ ) differed significantly with respect to slope (ANOVA for the conditional sum of squares, $F_{1,3}=5.51, P=0.0197$ ) and to intercept (ANOVA for the conditional sum of squares, $\left.F_{1,3}=35.8, P<0.0001\right)$. If the effects of exposure time to the experimental treatment were accounted for, PP metamorphs (13.4 mm) were significantly larger than EP metamorphs $(12.7 \mathrm{~mm})$ (ANCOVA, $\mathrm{F}_{1,239}=35.13, \mathrm{P}<0.0001$ ).

The body condition of PP metamorphs averaged 0.253 $( \pm 0.09 \mathrm{SE})$ regardless of the date of metamorphosis, whereas that of EP metamorphs decreased continuously with the exposure time to treatment (linear regression model: Condition index $=0.346-0.0412 *$ day; $R^{2}=10.5 \%$, $F_{1,124}=14.44, P=0.0002$ ) (Fig. 3B). If the effects of exposure time to the experimental treatment were accounted for, PP metamorphs had a significantly higher condition than EP metamorphs (least square mean: $-0.238 \pm 0.06 \mathrm{SE}$, ANCOVA, $F_{1,239}=15.75, P=0.0001$ ). 

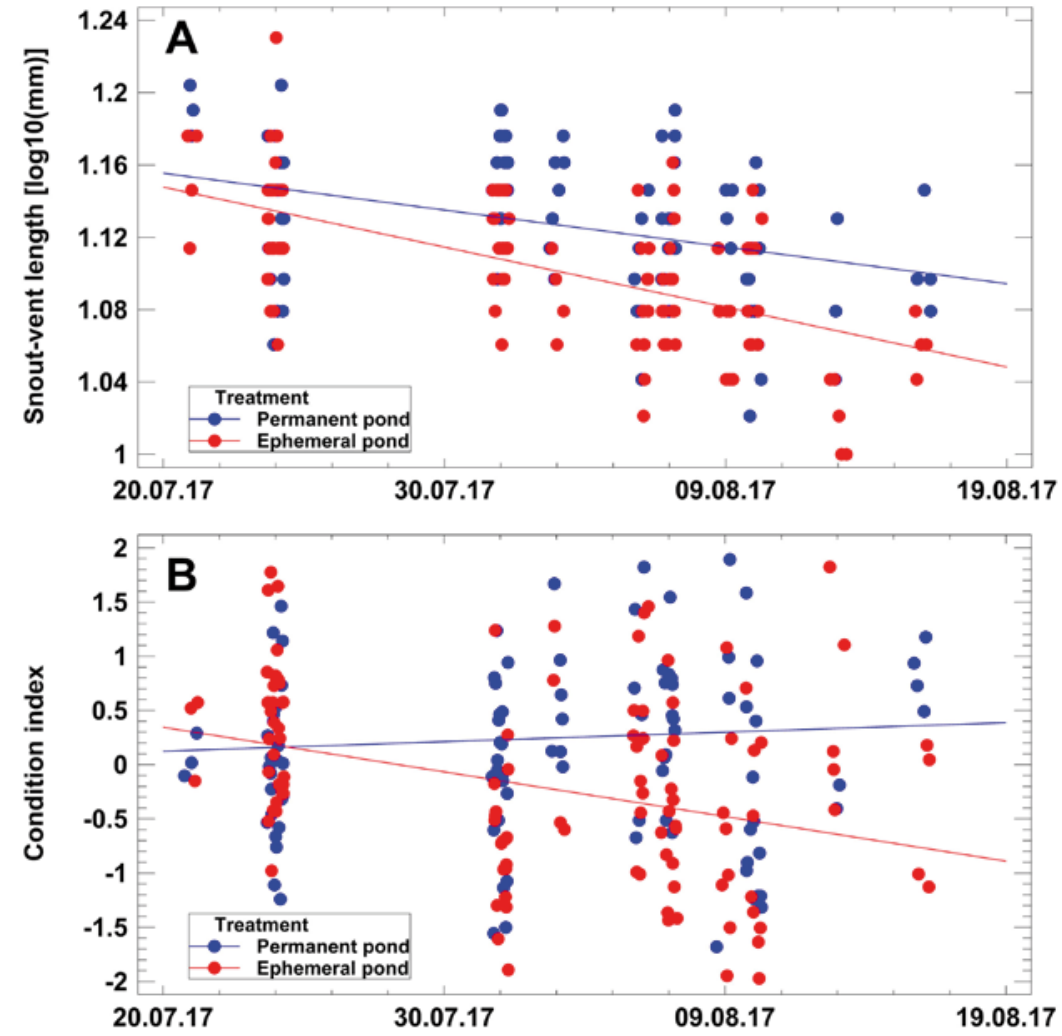

Figure 3. Temporal variation of snout-vent length (A) and condition index (B) in B. variegata metamorphs originating from the two experimental treatments. Each symbol represents a metamorph individual, the regression lines are given separately for the PP (blue) and for EP (red) treatments. For statistical details see text.

\section{Metamorph jumping performance}

During test trials, 113 out of 115 PP metamorphs and 92 out of 125 EP metamorphs responded to the initial tactile stimulus with at least one jump. Consequently, 2 PP metamorphs and 33 EP metamorphs were excluded from further analyses.

\section{Intensity of locomotor escape behaviour}

The number of spontaneous jumps was significantly greater in EP metamorphs (5.7 on average) than in PP metamorphs (3.7; ANCOVA, $F_{1,204}=17.93, P<0.0001$ ). Body condition was positively related to the number of spontaneous jumps (ANCOVA, $F_{1,204}=10.34, P=0.0015$ ), whereas SVL was not (ANCOVA, $F_{1,204}=1.04, P=0.3083$ ). The number of spontaneous jumps increased slightly, but significantly with body condition in PP metamorphs (linear regression model: $\log 10$ ( $n$ jumps $)=0.460+0.098 *$ body condition; $\left.\mathrm{R}^{2}=8.8 \%, \mathrm{~F}_{1,112}=10.65, \mathrm{P}=0.0015\right)$, but not in EP metamorphs $\left(R^{2}=1.7 \%, F_{1,91}=1.57, P=0.2136\right)$.

\section{Length of first jump}

The distance covered with the first jump was independent from the larval treatment (ANCOVA, $F_{1,204}=0.76$, $\mathrm{P}=0.3842$ ), but increased significantly with metamorph size (ANCOVA, $F_{1,204}=46.10, P<0.0001$ ) and body condition (ANCOVA, $\mathrm{F}_{1,204}=9.17, \mathrm{P}=0.0028$ ). The multiple regression models for the length of the first jump were log10 (jump1 length) $=1.072+0.059 * S V L+0.037 *$ body condition (PP metamorphs; $\mathrm{R}^{2}=29.2 \%, \mathrm{~F}_{2,112}=22.73$, $\mathrm{P}<0.0001$ ), and log10(jump1 length) $=1.122+0.054 * S V L$

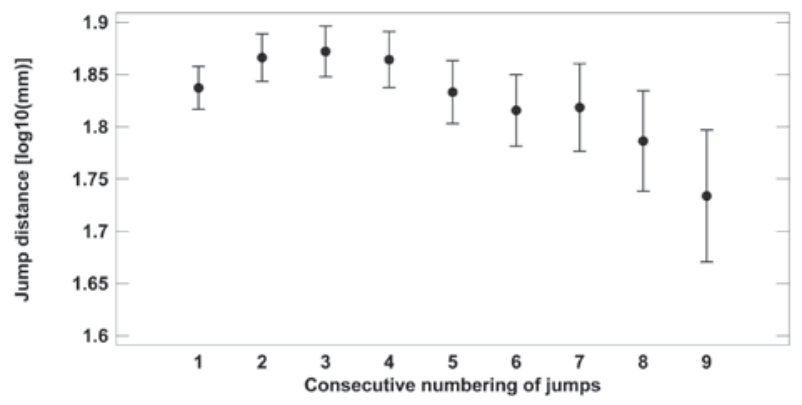

Figure 4. Distance covered by spontaneous, consecutive jumps of $B$. variegata metamorphs originating from the two experimental treatments. Each symbol represents the least square mean (with corresponding $95 \%$ Bonferroni confidence interval) calculated in a 2-factor ANCOVA with jump number and treatment as fixed factors and SVL and condition index as continuous co-variables. For statistical details see text.

+0.022 * body condition (EP metamorphs; $R^{2}=12.2 \%$, $\mathrm{F}_{2,91}=6.21, \mathrm{P}=0.0030$ ). The first four spontaneous jumps were significantly longer than the subsequent jumps (2-factor ANCOVA, $F_{8,918}=5.39, P<0.0001$; Fig. 4).

\section{Burst performance}

The total distance covered in all spontaneous jumps was significantly shorter in PP metamorphs than in $E P$ metamorphs (least square mean \pm SE: $204 \pm 1 \mathrm{~mm}$ vs. $332 \pm 2 \mathrm{~mm}$, ANCOVA, $\left.F_{1,204}=15.81, P=0.0001\right)$, and 


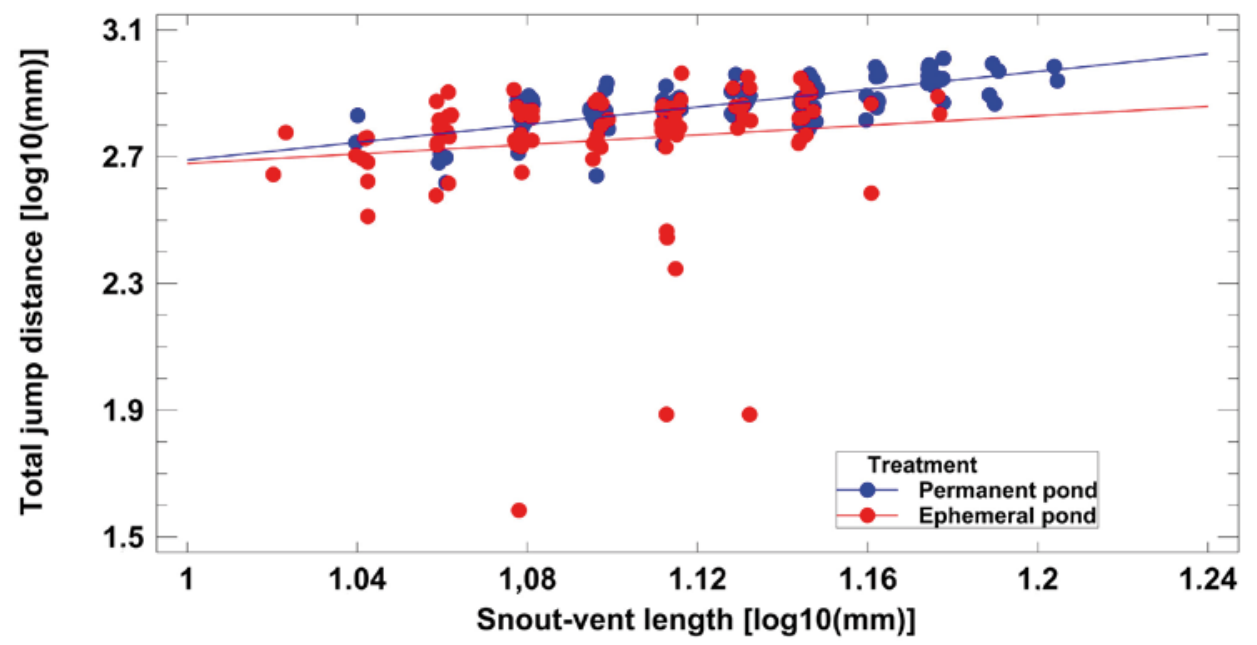

Figure 5. Variation of the cumulated distance covered within 10 jumps (spontaneous and forced) with respect to the snout-vent length of $B$. variegata metamorphs originating from the two experimental treatments. Each symbol represents a metamorph individual, the regression lines are given separately for the PP (blue) and for EP (red) treatments. For statistical details see text.

increased significantly with metamorph size (ANCOVA, $\mathrm{F}_{1,204}=14.07, \mathrm{P}=0.0002$ ) and body condition (ANCOVA, $\left.\mathrm{F}_{1,204}=17.38, \mathrm{P}<0.0001\right)$. The multiple regression models for the total distance covered in all spontaneous jumps were $\log 10$ (burst performance) $=1.213+0.083 * S V L+$ 0.131 *body condition (PP metamorphs; $R^{2}=17.3 \%$, $F_{2112}=11.51, P<0.0001$ ), and $\log 10$ (burst performance) $=1$. $163+0.073 * S V L+0.076 *$ body condition (EP metamorphs; $R^{2}=12.2 \%, F_{2,91}=3.41, P=0.0375$ ).

\section{Endurance}

The distance covered in 10 consecutive jumps was significantly larger in PP metamorphs than in EP metamorphs (least square mean \pm SE: $703 \pm 1 \mathrm{~mm}$ vs. $598 \pm 1 \mathrm{~mm}$, ANCOVA, $\left.\mathrm{F}_{1,191}=8.25, \mathrm{P}=0.0045\right)$, and increased significantly with metamorph size (ANCOVA, $F_{1,191}=17.06, P=0.0001$ ), but not with body condition (ANCOVA, $F_{1,191}=3.44, P=0.0651$ ). A closer inspection on size dependence showed that endurance and size were positively correlated in PP metamorphs ( $\log 10$ (total distance) $=1.29+1.40 * \log 10(\mathrm{SVL}) ; \mathrm{R}^{2}=48.2 \%, \mathrm{~F}_{1.99}=91.14$, $P<0.0001)$, but not in EP metamorphs $\left(R^{2}=1.7 \%\right.$, $F_{1,91}=1.57, P=0.2136$; Fig. 5).

\section{DISCUSSION}

Our study evidences that the environment experienced during tadpole development affects predictably the phenotype of $B$. variegata metamorphs. Size and performance of most metamorphs originating from the permanent pond treatment were superior to those of metamorphs from the ephemeral pond treatment. These carry-over effects might influence survival of the early terrestrial stage because small metamorphs experience a greater predation risk than large ones (Schäfer et al., 2018). Despite the fact that the hydroperiod of water bodies chosen for reproduction is unpredictable for the adult toads, they show a remarkable philopatry instead of spreading the risk by depositing clutches in different ponds (Kapfberger, 1984; Seidel, 1987; Barandun \& Heyer, 1997b, 1998). Consequently, the same breeding water body may change between permanent pond conditions and desiccating puddle during the reproduction period depending on the unpredictable rainfall regime (Hantzschmann \& Sinsch, 2019). As a spatial bet-hedging strategy seems to be absent in $B$. variegata, the range of variation of water level at the breeding pond is crucial for the survival of the aquatic stages and determines the chance that an individual successfully completing metamorphosis reaches sexual maturity. We discuss the consequences of changing water levels and associated environmental factors for the fitness of offspring reaching the terrestrial stage.

\section{Prediction 1: Larval conditions determine timing of metamorphosis and metamorph phenotype}

In contrast to the predictions of life-history theory, but in agreement with Kapfberger (1984) and Böll (2002), $B$. variegata tadpoles were unable to accelerate larval development in response to simulated EP conditions. An adaptive trade-off between timing of metamorphosis and sizeatmetamorphosis during theEPtreatment wasabsent, but smaller metamorph size than that of PP metamorphs indicates that EP conditions implies additional costs for development possibly due to increased stress (crowding effect mediated by CRH; Kapfberger, 1984; Denver, 1997; Brady \& Griffiths, 2000; Crespi \& Warne, 2013; Bredeweg et al., 2019). The high risk of death in desiccating ponds and developmental constraints leading to low-quality metamorph phenotypes (small size, low body condition) raise the question why $B$. variegata often reproduces in water bodies prone to drying-out. Our experimental data support the field observation that predator avoidance or reproductive failure in ponds containing aquatic predators is not a major factor in breeding site choice (Barandun \& Reyer, 1997b; Hartel et al., 2007). The presence of competing tadpoles from other species in permanent ponds does not seem to matter either (Barandun \& Reyer, 1997b). High-quality metamorphs emerge mainly from ponds with long hydroperiod, in 
sunny patches of the forest (Hartel et al., 2007; Scheele et al., 2014; Dittrich et al., 2016). Therefore, we propose that the surprising variety of water bodies used by $B$. variegata for spawning is simply a side product of a temporal bet-hedging strategy to increase reproductive success in rainy years when the hydroperiod of ephemeral ponds allows for successful metamorphosis (Buschmann, 2002). Since larval conditions in fact predict metamorph phenotype, carry-over effects with respect to size and body condition are crucial for the vulnerability of metamorphs to terrestrial predators (Schäfer et al., 2018).

\section{Prediction 2: Metamorph phenotypes differ in jumping performance}

The locomotor performance of anuran metamorphs during dispersal from the breeding water body to suitable juvenile habitats is often related to conditions experienced during the larval stage and to metamorph size (e.g., JohnAlder \& Morin, 1990; Goater et al., 1993; Tejedo et al., 2000; Charbonnier \& Vonesh, 2015; Bredeweg et al., 2019). Our study corroborates that there are complex interactions among larval environment, metamorph size, body condition and locomotor performance of $B$. variegata. Metamorph size and condition predict partially different aspects of locomotor performance (length of first jump, burst performance, endurance) demonstrating the importance of phenotype for metamorph fitness. The burst performance of EP metamorphs exceeded that of PP metamorphs, suggesting that their energy expenditure for escape jumps is greater. In EP metamorphs, low body condition and probably stress experienced during the larval stage seem to mediate a stronger sensitivity to a tactile stimulus than in PP metamorphs, similar to findings in Lithobates sylvaticus (Crespi \& Warne, 2013), but in contrast to Pelobates cultripes (Zamora-Camacho $\&$ Aragon, 2019). If the assumed stress-induced activity indeed overrides the limitations posed by muscle mass (e.g., Choi et al., 2003), the locomotor escape behaviour of EP metamorphs is less affected by size or condition than in PP metamorphs. Endurance showed the opposite pattern suggesting an overall greater locomotor performance of PP metamorphs than of same-sized EP metamorphs, as also shown for Rana aurora (Bredeweg et al., 2019). Finally, we provide evidence that the intensity of locomotor escape behaviour (number of consecutive spontaneous jumps) of $B$. variegata metamorphs has a size-independent component, which relates directly to the conditions experienced during the larval stage. Thus, morphological and behavioural traits of metamorphs determine in part their locomotor performance, i.e. dispersal distance and response to predator attacks.

\section{Prediction 3: Similar phenotypes resulting from either larval treatment have similar post-metamorphic performance}

Conditions experienced during the larval stage can have delayed effects on post-metamorphic growth not captured in the size of the metamorph when leaving the aquatic environment (Van Allen et al., 2010; Bredeweg et al., 2019). Therefore, similar phenotypes may differ in their performance, if they have experienced different larval environment. Here, we provide clear evidence that the locomotor component of escape behaviour (frequency of jumps, endurance) is not predictable from metamorph size or condition alone but differs in samesized metamorphs between the larval treatments. We conclude that metamorphs originating from distinct larval environments are not equivalent in post-metamorphic performance and have most probably different survival rates, even if they share similar phenotypes. Since locomotor performance is also a proxy for dispersal ability, the bearing on the structure and demography of the adult population is straightforward.

In summary, the outdoor mesocosm experiment gives deeper insight in the consequences of breeding site features for aquatic development and subsequent carry-over effects on the early terrestrial stages of yellowbellied toads. The time course of water level fluctuation, unpredictable at clutch deposition, may lead to high- and low-quality metamorphs in the same pond during the prolonged reproduction period depending on the rainfall regime. Thus, a breeding water body may alternate between sink and source state within one year and between years indicating that the observed breeding site fidelity is a temporal bet-hedging strategy.

\section{Implications for conservation management}

Since $B$. variegata has recently experienced local extinctions, habitat fragmentation and population declines in western and north-western parts of its range, informed conservation management requires deeper insight in the ecological consequences of breeding habitat design (e.g., Cayuela et al., 2011; Scheele et al., 2014; Guicking et al., 2017; Weihmann et al., 2019). Larval mortality due to desiccation is probably more frequent than previously perceived and promoted by the focus on very shallow artificial ponds in breeding site management (e.g., Wagner, 1996; Zahn \& Niedermeier, 2004). Water bodies used for breeding are not equivalent in habitat quality, even if their hydroperiod is long enough to allow tadpoles to complete metamorphosis. Metamorphs hatching from ephemeral ponds have a lower fitness due to carry-over effects on phenotype and behaviour. Thus, timing of and size at metamorphosis of $B$. variegata does not follow strictly the predictions of the Wilbur and Collins (1973) model suggesting that larval growth trajectories in this species are not adapted to conditions in ephemeral breeding sites with short hydroperiods. Conservation management of endangered $B$. variegata populations should thus include the construction of shallow, but permanent water bodies when attempting to optimize breeding habitats.

\section{ACKNOWLEDGEMENTS}

We thank the Struktur- und Genehmigungsdirektion Nord in Koblenz for the support and providing the permits for field study and laboratory experiments, as well as the Heinrich Böll foundation for financial commitment. An earlier version of the manuscript benefitted by comments from F.J. Zamora-Camacho, S. Maddock and an anonymous reviewer. 


\section{REFERENCES}

Alford, R. A. \& Harris, R. N. (1988). Effects of larval growth history history on anuran metamorphosis. American Naturalist 131, 91-106.

Altwegg, R. \& Reyer, H. U. (2003). Patterns of natural selection on size at metamorphosis in water frogs. Evolution 57(4), 872-882. doi:10.1111/j.0014-3820.2003.tb00298.x

Álvarez, D. \& Nicieza, A. G. (2002a). Effects of induced variation in anuran larval development on postmetamorphic energy reserves and locomotion. Oecologia 131(2), 186195. doi:10.1007/s00442-002-0876-x

Álvarez, D. \& Nicieza, A. G. (2002b). Effects of temperature and food quality on anuran larval growth and metamorphosis. Functional Ecology 16(5), 640-648. doi:10.1046/j.1365-2435.2002.00658.x

Băncilă, R. I., Hartel, T., Plaiasu, R., Smets, J. \& Cogălniceanu, D. (2010). Comparing three body condition indices in amphibians: a case study of yellow-bellied toad Bombina variegata. Amphibia-Reptilia 31(4), 558-562. doi:10.1163/017353710x518405

Barandun, J. \& Reyer, H. U. (1997a). Reproductive ecology of Bombina variegata: development of eggs and larvae. Journal of Herpetology 31(1), 107-110. doi:10.2307/1565337

Barandun, J. \& Reyer, H. U. (1997b). Reproductive ecology of Bombina variegata: characterisation of spawning ponds. Amphibia-Reptilia 18(2), 143-154.

Barandun, J. \& Reyer, H. U. (1998). Reproductive ecology of Bombina variegata: habitat use. Copeia 1998(2), 497-500.

Beckerman, A., Benton, T. G., Ranta, E., Kaitala, V. \& Lundberg, P. (2002). Population dynamic consequences of delayed life-history effects. Trends in Ecology \& Evolution 17(6), 263-269. doi:10.1016/S0169-5347(02)02469-2

Böll, S. (2002). Ephemere Laichgewässer: Anpassungsstrategien und physiologische Zwänge der Gelbbauchunke (Bombina variegata) in einem Lebensraum mit unvorhersehbarem Austrocknungsrisiko. (PhD), Bayerische Julius-MaximiliansUniversität Würzburg, Würzburg.

Boes, M. W., \& Benard, M. F. (2013). Carry-Over Effects in Nature: Effects of Canopy Cover and Individual Pond on Size, Shape, and Locomotor Performance of Metamorphosing Wood Frogs. Copeia 2013(4), 717-722. doi:10.1643/CE-12-091

Brady, L. D. \& Griffiths, R. A. (2000). Developmental responses to pond desiccation in tadpoles of the British anuran amphibians (Bufo bufo, B.calamita and Rana temporaria). Journal of Zoology 252, 61-69.

Bredeweg, E. M., Urbina, J., Morzillo, A. T. \& Garcia, T. S. (2019). Starting on the Right Foot: Carryover effects of larval hydroperiod and terrain moisture on post-metamorphic frog movement behavior. Frontiers in Ecology and Evolution 7. doi:10.3389/fevo.2019.00097

Briggs, V. S. (2008). Mating patterns of red-eyed treefrogs, Agalychnis callidryas and A. moreletii. Ethology 114, 489498. doi:10.1111/j.1439-0310.2008.01490.x

Buschmann, H. (2002). Fecundity of yellow-bellied toads Bombina variegata under free-range conditions: an indication of risk-spreading strategy. Amphibia-Reptilia 23(3), 362-369.

Cayuela, H., Cheylan, M. \& Joly, P. (2011). The best of a harsh lot in a specialized species: breeding habitat use by the yellow-bellied toad (Bombina variegata) on rocky riverbanks. Amphibia-Reptilia 32(4), 533-539. doi:10.1163/156853811X614461

Charbonnier, J. F. \& Vonesh, J. R. (2015). Consequences of life history switch point plasticity for juvenile morphology and locomotion in the Tungara frog. PeerJ 3. doi:10.7717/ peerj.1268

Chelgren, N. D., Rosenberg, D. K., Heppell, S. S. \& Gitelman, A. I. (2006). Carryover aquatic effects on survival of metamorphic frogs during pond emigration. Ecological Applications 16(1), 250-261. doi:10.1890/04-0329

Choi, I., Shim, J. H., \& Ricklefs, R. E. (2003). Morphometric relationships of take-off speed in anuran amphibians. Journal of Experimental Zoology Part A: Comparative Experimental Biology 299A(2): 99-102. doi:10.1002/ jez.a.10293

Crespi, E. J. \& Warne, R. W. (2013). Environmental conditions experienced during the tadpole stage alter postmetamorphic glucocorticoid response to stress in an amphibian. Integrative and Comparative Biology 53(6), 989-1001. doi:10.1093/icb/ict087

De Block, M. \& Stoks, R. (2005). Fitness effects from egg to reproduction: Bridging the life history transition. Ecology 86(1), 185-197. doi:10.1890/04-0116

Denver, R. J. (1997). Environmental stress as a developmental cue: corticotrophin-releasing hormone as a proximate mediator of adaptive phenotypic plasticity in amphibian metamorphosis. Hormones and Behavior 31, 1169-1179.

Denver, R. J. \& Middlemis-Maher, J. (2010). Lessons from evolution: developmental plasticity in vertebrates with complex life cycles. Journal of Developmental Origins of Health and Disease 1(5), 282-291. doi:10.1017/ s2040174410000279

Di Cerbo, A. R. \& Biancardi, C. M. (2010). Morphometric study on tadpoles of Bombina variegata (Linnaeus, 1758) (Anura; Bombinatoridae). Acta Herpetologica 5(2), 223-231.

Dittrich, C., Drakulić, S., Schellenberg, M., Thein, J. \& Rödel, M. O. (2016). Some like it hot? Developmental differences in Yellow-bellied Toad (Bombina variegata) tadpoles from geographically close but different habitats. Canadian Journal of Zoology 94(2), 69-77. doi:10.1139/cjz-2015-0168

Goater, C. P., Semlitsch, R. D. \& Bernasconi, M. V. (1993). Effects of body size and parasite infection on the locomotory performance of juvenile toads, Bufo bufo. Oikos 66, 129136. doi:10.2307/3545205

Gosner, K. L. (1960). A simplified table for staging anuran embryos and larvae with notes on identification. Herpetologica 16, 183-190.

Gritti, E. S. \& Barbot, B. (2019). Developmental Plasticity. In V. Zeigler-Hill \& T. K. Shackelford (Eds.), Encyclopedia of Personality and Individual Differences (pp. 1-3). Cham: Springer International Publishing. doi:10.1007/978-3-31928099-8

Guicking, D., Finke, L., Wittich, M., Pfeiffer, I., Veith, M., Geske, C., Braukmann, U., Weising, K. \& Neubeck, C. (2017). Conservation genetics of Bombina v. variegata (Anura: Bombinatoridae) in northern Hesse, Germany. Salamandra 53(2), 201-211.

Hantzschmann, A. M. \& Sinsch, U. (2019). Struktur und dynamik von gelbbauchunken-populationen (Bombina variegata) im Westerwald - Konsequenzen für das regionale ArtenschutzManagement. Zeitschrift für Feldherpetologie 26(2), 218-235. 
Hartel, T., Nemes, S. \& Mara, G. (2007). Breeding phenology and spatio-temporal dynamics of pond use by the yellow-bellied toad (Bombina variegata) population: the importance of pond availability and duration. Acta Zoologica Lituanica 17(1), 56-63. doi:10.1080/13921657.2007.10512816

John-Alder, H. B. \& Morin, P. J. (1990). Effects of larval density on jumping ability and stamina in newly metamorphosed Bufo woodhousii fowleri. Copeia 1990(3), 856-860. doi:10.2307/1446453

Kapfberger, D. (1984). Untersuchungen zu populationsaufbau, wachstum und ortsbeziehungen der gelbbauchunke, Bombina variegata variegata (Linnaeus, 1758). Zoologischer Anzeiger 212, 105-116.

McGinley, R.H., Prenter, J. \& Taylor, P.W. (2013). Whole-organism performance in a jumping spider, Servaea incana (Araneae: Salticidae): links with morphology and between performance traits. Biological Journal of the Linnean Society 110, 644-657. doi:10.1111/bij.12155

Miesler, M. \& Gollmann, B. (2000). Populationsstruktur, Wachstum und Fortpflanzung der Gelbbauchunke, Bombina variegata (LINNAEUS, 1758): Ergebnisse aus einer Ein-Jahres-Studie im Lainzer Tiergarten (Wien, Österreich). Herpetozoa 27(1/2), 45-54.

Mikoláš, P. (2016). Can Change of Landscape Composition Increase Interspecies Competition among amphibians and thus decrease the body condition of the endangered Bombina variegata? Polish Journal of Environmental Studies 25(6), 2527-2532. doi:10.15244/pjoes/62798

Moore, M. P. \& Martin, R. A. (2019). On the evolution of carryover effects. Journal of Animal Ecology. doi:10.1111/13652656.13081

Morey, S. \& Reznick, D. (2001). Effects of larval density on postmetamorphic spadefoot toads (Spea hammondii). Ecology 82(2), 510-522. doi:10.2307/2679876

Newman, R. A. (1998). Ecological constraints on amphibian metamorphosis: interactions of temperature and larval density with responses to changing food level. Oecologia 115, 9-16.

Pechenik, J. A. (2006). Larval experience and latent effectsmetamorphosis is not a new beginning. Integrative and Comparative Biology 46(3), 323-333. doi:10.1093/icb/icj028

Reading, C. J. (2007). Linking global warming to amphibian declines through its effects on female body condition and survivorship. Oecologia 151(1), 125-131. doi:10.1007/ s00442-006-0558-1

Richards, C. M. (1958). The inhibition of growth in crowded Rana pipiens tadpoles. Physiological Zoology 31, 138-151.

Richter-Boix, A., Llorente, G. A. \& Montori, A. (2006). Effects of phenotypic plasticity on post-metamorphic traits during pre-metamorphic stages in the anuran Pelodytes punctatus. Evolutionary Ecology Research 8(2), 309-320.

Schäfer, A., Schäfer, F., Wagner, T. \& Sinsch, U. (2018). Carabid predation on Bombina variegata metamorphs: size at and timing of metamorphosis matter. Salamandra 54(3), 222-228.

Scheele, B. C., Boyd, C. E., Fischer, J., Fletcher, A. W., Hanspach, J. \& Hartel, T. (2014). Identifying core habitat before it's too late: the case of Bombina variegata, an internationally endangered amphibian. Biodiversity and Conservation 23(3), 775-780. doi:10.1007/s10531-014-0624-7
Seidel, B. (1987). Breeding of a Bombina variegata population in a habitat with temporary pools. Proceedings of 4th Ordinary General Meeting of the Societas Europea Herpetologica, Nijmegen 1987, 353-356.

Stearns, S. C. (2000). Life history evolution: successes, limitations, and prospects. Naturwissenschaften 87(11), 476-486. doi:10.1007/s001140050763

Tarvin, R. D., Silva Bermúdez, C., Briggs, V. S. \& Warkentin, K. M. (2015). Carry-over effects of size at metamorphosis in red-eyed treefrogs: Higher survival but slower growth of larger metamorphs. Biotropica 47(2), 218-226. doi:10.1111/ btp.12198

Tejedo, M., Semlitsch, R. D. \& Hotz, H. (2000). Covariation of morphology and jumping performance in newly metamorphosed water frogs: Effects of larval growth history. Copeia 2000(2), 448-458.

Turner, A. M., Bernot, R. J. \& Boes, C. M. (2000). Chemical cues modify species interactions: the ecological consequences of predator avoidance by freshwater snails. Oikos 88(1), 148-158. doi:10.1034/j.1600-0706.2000.880117.x

Van Allen, B. G., Briggs, V. S., McCoy, M. W. \& Vonesh, J. R. (2010). Carry-over effects of the larval environment on postmetamorphic performance in two hylid frogs. Oecologia 164(4), 891-898. doi:10.1007/s00442-010-1728-8

Vonesh, J. R. (2005). Sequential predator effects across three life stages of the African tree frog, Hyperolius spinigularis. Oecologia 143(2), 280-290. doi:10.1007/s00442-004-1806-x

Wagner, T. (1996). Untersuchungen zum aquatischen Lebensraum der Gelbbauchunke, Bombina v. variegata (Linnaeus, 1758), als Grundlage für Pflege-und Entwicklugskonzepte. Naturschutzreport 11, 32-46.

Weihmann, F., Weihmann, S. \& Weihmann, T. (2019). Conservation genetic analysis of a Central-European rangemargin population of the yellow-bellied toad (Bombina v. variegata). Conservation Genetics 20(3), 557-569.. doi:10.1007/s10592-019-01156-6

Wilbur, H. M. \& Collins, J. P. (1973). Ecological aspects of amphibian metamorphosis. Science 182(4119), 1305-1314. doi:10.1126/science.182.4119.1305

Yagi, K. T. \& Green, D. M. (2018). Post-metamorphic carry-over effects in a complex life history: Behavior and growth at two life stages in an amphibian, Anaxyrus fowleri. Copeia 106(1), 77-85. doi:10.1643/ce-17-593

Zahn, A. \& Niedermeier, U. (2004). Zur Reproduktionsbiologie von Wechselkröte (Bufo viridis), Gelbbauchunke (Bombina variegata) und Laubfrosch (Hyla arborea) im Hinblick auf unterschiedliche Methoden des Habitatmanagements. Zeitschrift für Feldherpetologie 11(1), 41-64.

Zamora-Camacho, F. J., \& Aragón, P. (2019). Failed predator attacks have detrimental effects on antipredatory capabilities through developmental plasticity in Pelobates cultripes toads. Functional Ecology 33(5): 846-854. doi:10.1111/1365-2435.13308

Zamora-Camacho, F. J., Cortés-Manzaneque, S. \& Aragón, P. (2019). Simulated predation pressure in Pelobates cultripes tadpoles modulates morphology at the metamorphic stage. Current Zoology. doi:10.1093/cz/zoy097

Accepted: 19 January 2020

Please note that the Supplementary Materials are available via the Herpetological Journal website: https://thebhs.org/publications/the-herpetological-journal/volume-30-number3-july-2020 